\title{
O MITO ÉPICO NA FICÇÃO BRASILEIRA
}

\author{
Roberto de Oliveira Brandão*
}

\begin{abstract}
RESUMO
Opresente estudo procura analisar duas obrassignificativas da literatura brasileira: O Guarani (1857) e Os Senōes (1902) sob a pespectiva do milo épico. Essas obras surgiram em periodos estratégicos da literatura e da vida brasileiras. a primeira promovendo a unjficação dos ideais de formação da nacionalidade (sentido etforico) tipicos do Romantismo, a segunda. operando a iomada de consciêncio dos impasses vividos pela sociedade brasileira da époco (sentido disforico). fase representada pela literatura do Pré-Modernismo. Embora diametralmente opostas, ambas se integram na tradiçäo mimético-retórica cumprida pelo género épico.
\end{abstract}

Uniternos: O mito épico na fiç̧āo brasileira: Épica e/iterattura: Mito e literatura: O Guarani $e$ Os Sertöes: Retórica e literatira.

\section{No início era a ordem}

É já lugar comum afirmar-se que o romance, como forma literária, tem sua origem na épica antiga. Os moldes e os exemplos épicos que iriam alimentar o romance tiveram grande florescimento na Antigüidade Clássica. Homero aparece como o lendário fundador dessa tradição e Aristóteles é seu primeiro e mais famoso teorizador. Este distingüia as artes a partir de três critérios:

Os meios: ritmo, linguagem, cores, mármore etc., com base nos quais se distinguiam a literatura, a pintura, a escultura c outras formas artisticas;

Os objetos: seres melhores, piores ou iguais a nós ou aos que nós conhecemos, escala que servia para separar a tragédia e a epopéia, que exigiam personagens elevadas social e eticamente, da comédia, que admitia tipos humanos de condição humilde;

\footnotetext{
* Pror. de Literatura Brasileira na FFLCH/USP.
} 
As maneiras: a lírica, em que o poeta falava por si, a épicả, em que a representação assumia a forma de narrativa e o drama, em que as personagens agiam em cena.

Esse esquema permaneceu por muito tempo como critério efetivo de produção e de avaliação das obras. Com base nele se podia afirmar que a lírica era a expressão do sentimento e que o sujeito lírico manifestava sua experiência interior diretamente, sem outra mediação que a fala pessoal e intransferivel. Ele deixava-se levar pelo livre movimento do espírito.

A épica, por sua vez, descrevia o mundo mediado pela vontade. O herói, figura central da narrativa épica, devia ser superior a nós, pois sua tarefa estava acima da do homem comum. Mediadora simbólica dos nossos desejos e necessidades, a personagem épica era ao mesmo tempo porta-voz, exemplo c representante da comunidade. Do ponto de vista da épica antiga, a idéia de um herói que agisse por si e para si seria impensável. Vontade, determinação, capacidade de realização, cram algumas de suas virtudes. A litcratura épica cumpria com esses requisitos sua função pedagógica de atuar como modelo a ser seguido pelo cidadão da polis antiga.

A personagem dramática representava o jogo do destino $\mathrm{em}$ sua inelutabilidade. Ele vivia o precário equilíbrio entre o dado e o possivel, entre as regras de conduta e o real que lhes escapava. Sua ação ia até ao ponto $\mathrm{cm}$ que se revelava impotente diante de uma força superior, de um saber que, quando chegava, se mostrava inútil.

Mas essas categorias se desdobram em outras, já que os gêneros querem ser formas arquetípicas, válidas fora do tempo em que foram estabelecidas. A lírica, mesmo alimentando-se do passado e do futuro, integra-se ao presente como seu centro efetivo. $\mathrm{Na}$ verdade, a lírica só conhece o presente, pois a emoção viva é intransferivel, não admite mediação. A épica, por sua vez, exige distanciamento. Seu tempo $\dot{c}$ o passado, embora um passado que pode ser trazido ao presente pela memória. Se a lírica recupera o objeto enquanto sentimento, a épica o recria como forma plástica, como volume. Estruturalmente, o detalhe se perde na emoção lírica já quc cada momento lírico é um tempo completo e autônomo. $\mathrm{O}$ mundo épico é edificado pedra sobre pedra, com o capricho do geômetra que constrói um mural caprichoso. A instantaneidadc da sensação lírica contrasta com a demora do enredo épico. A emoção lírica é totalizante, icônica, o enredo épico é sequencial e articulado.

Por outro lado, face à tensão progressiva do drama, a épica apresenta uma estrutura paratática onde as açōes vão se desenvolvendo não tanto em função de um fim, como na catástrofe trágica, mas pelo próprio prazer da exposição. O tempo épico é consumido devagar, os resíduos e os segredos que ele deixa são apenas formas de manter interesse pelos fatos. É por isso que o narrador épico varia, acumula e alonga os detalhes de seus temas. $O$ cotejo poderia continuar indefinidamente, pois os gêneros tinham limites bem demarcados, com traços específicos e regras retóricas próprias.

\section{Do cosmo ao caos}

Embora herdeiro direto da épica, enquanto forma narrativa, o romance é um gênero moderno que atende a necessidades expressivas novas senão desconheeidas do homem antigo, ao menos pouco privilegiadas em seu sistema 
cultural e estético. Historicamente falando, o romance nasce das cinzas da narrativa épica. O Dom Quixote (Cervantes, 1605) tem função paródica em relação às novelas de cavalaria. O tom épico destas cai na representação do cavaleiro da triste figura. O sério, quase religioso dos ideais, da moral e do amor cavalheirescos dos séculos XIV eXV, torna-se cômico, aparece desfocado, incficaz, pois já não representa valores coletivos. Outro marco no caminho para o romance moderno, o Robson Crusoé (Defoe, 1719) tem de recompor, simbolicamente, é verdade, o ritual de possc do mundo. Desprovido dos instrumentos da civilização longamente desenvolvidos pelo homem, o náufrago solitário precisa reinventar, novamente com o suor do rosto, os meios para sua sobrevivência.

Cada um desses romances tem de recompor, à sua maneira, a ordem do mundo. Aquele, o mundo da ficção literária, este, o da civilização com todos os seus instrumentos e valores.

Depois das primeiras resistências enfrentadas pelo romance, ele eonhece um desenvolvimento muito grande. Diderot, no século XVIII, ao elogiar o romancista inglês Samuel Richardson (1689-1761), chega a desejar que se encontrasse outro nome para designar as obras desse autor, uma vez que o gênero romance era considerado "um tecido de acontecimentos quiméricos e frívolos cuja leitura era perigosa para o gosto e os costlmes", ao contrário das obras de Richardson que, ainda nas palavras de Diderot, "elevan o espirito, tocam a alma, respiram em tudo o amor ao bem". No mesmo estudo reconhece Diderot que aquilo que os moralistas (Montaigne, La Rochefoucauld e outros) tinham exposto em forma de máximas, o romancista inglês o fizera através da ação.

$\dot{E}$ interessante observar a expectativa dc um leitor como Diderot, que parece buscar no romance "verdades", "seriedade", "exemplos éticos", etc. Entre nós houve um professor do Colégio Pedro II do Rio de Janeiro que em 1889 colocava o romance entre o que ele chamava de "gêneros secundários de literatura", definido deste modo: "O romance propriamente dito, é uma série de fiç̧̃es com as quais o autor tem por fim deleitar e aperfeiçoar o coração de setus leitores". Lembremos que esses atributos eram os mesmos propostos pcla retórica antiga, formalizados no preceito horaciano do utile dulci.

Independentemente desscs focos de resistêneia conceitual, na prática o romance ia alargando as fronteiras formais e temáticas da antiga épica, até ao ponto em que ficará impossivel atribuir-lhe um espaço próprio. Em sua antropofagia ritual, o romance devora não apenas as virtudes de seu ancestral épico: o mito, a história, o didático, a narração $\mathrm{em}$ terceira pessoa, ete., mas também os outros gêneros e sub-gêneros em que o antigo sistema se foi dividindo. Mais do que isso, ele adquire uma capacidade sempre nova de misturar e de inventar formas e temas.

Fazendo o caminho inverso, podemos detectar no romance vestígios de sua antiga origem épica. É o que pretendemos no presente trabaiho. Para isso traçamos um grande arco ligando obras aparentemente tão distantes: O Guarani (1857) de José de Alencar e Os Sertões (1902) de Euclides da Cunha. Sob a perspectiva adotada, ambas cumpriram, nos respectivos periodos, papel simbólico importante tanto para nossa literatura como para nossa história. Uma inaugura na nossa fieção o mito nacional; a outra, em sua visão disfórica, representa a tomada de consciência de que o mito idílico, que vínhamos 
acalentando há tempo (desde os primeiros cronistas), era precário. A obra de Euclides da Cunha descobie, não apenas para o autor, mas para toda a nação que, sob a imagem romântica do "herói brasileiro" idealizado, havia uma multidão de scres subumanos. É o mito da unidade nacional que cai por terra, e nos vemos, pela primeira vez, na condição de subdesenvolvidos.

\section{O real e o mítico}

Épica e mito estão tradicionalmente ligados, embora o âmbito do segundo seja mais amplo, estendendo-se a outras formas artísticas. O termo mito implicava a noção de narrativa figurada como modo concreto de simbolizar fatos ou crenças coletivas. Mesmo se opondo à noção de logos (como atividade racional), muitas vezes a narrativa mítica foi utilizada pela filosófica para ilustrar um pensamento abstrato.

Historicamente o mito tem sido um modo peculiar de dar significado a certos fcnômenos que, de outro modo, seriam considerados pura realidade natural sem sentido. $O$ fato de ter existência simbólica, fora do tempo e do espaço concretos, confere-lhe uma capacidade de atender a necessidades expressivas e situações reais muito diferentes. $\dot{E}$ por isso que Fernando Pessoa diz: "O mito é o nada que é tudo".

Pensados nesse contexto, podemos afirmar que $O$ Guarani e Os Sertões apresentam enredos ancorados num substrato figurativo da realidade brasileira (realidade bruta, ainda sem scntido) que vai, aos poucos, assumindo dimensões miticas.

O ambiente natural onde se desenrola a ação do romance de Alencar é o interior do Rio de Janeiro do século XVII (1604), então "deserto e inculto", esclarece o autor. Mais precisamente, a habitação de D. Antônio de Mariz, "fidalgo português cota d'armas e um dos fiundadores do Rio de Janeiro", isto é, um nobre tradicional, com brazão próprio. Essa casa era autosuficiente, "um castelo feudal da Idade Média". Como descreve Alencar:

"esse torrão brasileiro, esse pedaço do sertão, não era senão um fragmento de Portugal live, de sua pátria primitiva; ai só reconhecia comoreiao duque de Bragança, legitimo herdeiroda coroa; e quando corriam as cortinas do dossel da sala, as armas que se viam, eram cinco quinas portuguesas, diante das quais todos as frontes se inclinavam" (p. 18).

Observamos que Alencar superpõe os signos da tradição portuguesa à realidade brasileira, espécie de lugar edĉnico anterior à civilização, sem lastro cultural e, portanto, natureza bruta. $O$ quadro natural é insistentemente ressaltado: o rio "Paquequer sallando de cascata em cascata"; a "Serra dos Örgãos "; as "flores silvestres das nossas matas "; o "perflume do benjoim"; a identificação entre o indigena e o tigre:

"estes dois selvagens do Brasil, cada um com suas armas, cada um com a consciência de sua força e de sua coragem" (p. 29).

Desse fundo natural desenvolve-se a atmosfera idilica do romance, naturalmente acrescido de peripécias necessárias ao interesse do leitor. As duas vertentes: a nobreza portuguesa e a natureza selvagem brasileira se fundem, 
ao fim, na imagem simbólica do dilúvio, destruição e preservação das espécies ao mesmo tempo. Ao perderem os laços que os ligavam ao passado (família, lugar, identidade), Peri e Ceci serão as sementes de um mundo novo, do mesmo modo que de Iracema e Martim nascerá Moacir, simbolicamente o primeiro brasileiro no projeto literário nacionalista de Alencar.

Também em $O s$ Sertões a natureza bruta antecede à presença e à ação humanas que lhe dão sentido. Aliás, a própria disposição fisica das partes da obra já revela sua dinâmica interna. Ela é composta por três grandes unidades: "A terra/O homem/A luta".

A primeira preocupação de Euclides é conhecer geologicamente a região em que se desenrolaria a Guerra de Canudos. Para isso ele vai, por um lado, levantando as impressões que o solo suscitava e, por outro, passando $\mathrm{em}$ revista hipóteses cientificas da época, positivismo, naturalismo, evolucionismo. Com base nessas teorias, tenta compreender os fenomenos naturais, relevo, clima, suas transformações, e os tipos humanos que lhes são peculiares. Não podemos nos esquecer que a obra resulta de uma reportagem jornalistica levada a efeito por Euclides em pleno campo de batalha, e também o fato de o texto ter sido exaustivamente trabalhado pelo autor. Daí a sensação de construção caprichosa. Cada palavra, cada frase e cada período revelam não apenas uma meticulosa preocupação de captar o traço correto do real, mas também preocupação metalingüistica, isto é, como expressão estilisticamente adequada.

Das três partes, a última é sem dúvida a mais interessante, pois concentra-se nas marchas e contramarchas das bataihas de Canudos. As duas primeiras ficam como pano de fundo, espécie de levantamento das coordenadas ou das razões históricas, sociais e culturais do surgimento de Antônio Conselheiro.

O livro começa descarnado, objetivo: "O planalto central do Brasil desce, nos Iitorais do sul, em escarpas inteiriças, altas e abruptas" (p.9). Por vezes, do puramente descritivo emerge o sentido histórico da realidade:

"Oobservador tem a impressão de seguir torneando a truncadura malgradada da borda de um planalto./ Calca, de fato, estrada três vezes secular, histórica vereda por onde avançavam os rudes sertanistas nas suas excursões para o interior./ Não a alteraram nunca./ Não a variou, mais tarde, a civilização, justapondo aos rastros do bandeirante os trilhos de uma viafërea" (p. 15).

Com respeito ao homem, a mesma preocupação de descrevê-lo enquanto objeto científico: "O brasileiro, tipo abstrato que se proctura, mesmo no casofavorável acima firmado, surge de um etrelaçamento consideravelmente complexo" (p. 59). Apoiando-se na ciência da época, Euclides ehega a conclusões categóricas, incluindo-se aí o tom enfático de certeza cientifica: "Não temos unidade de raça./ Não a teremos nunca" (p. 74), ou ainda: "Não há tipo antropológico brasileiro" (p. 74).

Do ponto de vista do debate sobre o "homem brasileiro" essas afirmaçōes estão longe, por exemplo, das fantasias literárias de Alencar, se lembrarmos de Moaeir (Iracema), simbolieamente o primeiro brasileiro. Por outro lado, essas formulações nos fazem pensar na figura de Macunaima, "herói sem nenhum caráter".

Mas, voltando ao texto de Euclides, observamos que mesmo nas 
descrições retoricamente objetivas do inicio, vão surgindo, aqui e ali, os primeiros indícios que posteriormente culminarão na atmosfera mitica que envolve a figura principal da narrativa. Ao descrever um momento de transformação da natureza, quando "Sobre o solo, que as amarilis atapetam, resurge triunfalmente a flora tropical", o narrador-repórter usará uma de suas frases curtas e emblcmáticas: "E o serfão é um paraíso" (pgs. 4l-3). Por vezes são os fenômenos naturais que se libertam das leis que os regem, assumindo formas próprias e originais. Se discute sobre o quadro climático do Brasil, Euclides reconhece: "De fato, o clima ai inteiramente subordinado ao facies geográfico, viola as leis gerais que o regulam" (p. 61).

$E$ os tipos humanos, quando não causam admiração pela fraqueza enganosa, surpreendem o mais objetivo dos obscrvadores:

"Reproduzamos, intactas, todas as impressóes, verdadeiras ou ilusórias, que tivemos quando, de repente, acompanhamos a celeridade de uma marcha militar, demos de frente, numa volta do sertāo, com aqueles desconhecidos singulares que ali estäohá três séculos" (p. 93).

Temos ai um traço estilístico de Euclides. Depois de descrever "objetivamente" um fato, coloca uma frase que o interpreta, não mais no plano da realidade, mas dos pontos de vista cientifico, histórico, social, mítico, ctc., estabelecendo uma relação padadoxal entre a realidade bruta e seu sentido cultural.

\section{As marcas épicas}

Como nas epopéias antigas cada personagem possuia epítetos que os acompanhavam como emblemas de suas qualidades, em $O$ Glarani distinguimos designaçōes que imobilizam as personagens no seu caráter padrão, formando grupos funcionais na obra.

No topo da escala ontológica c ética temos expressões que configuram a situação social e hierárquica das personagens. Em primeiro lugar vêm os títulos de nobreza recebidos como bens herdados, depois os que expressam uma "nobreza natural e espontânea". Assim é que se repetem termos como: "cavalheiro", "fidalgo", "nobreza do coração superior", etc.

As mulheres se caracterizam pela vaidade, religiosidade, pela ambição de reinar pela fraqueza, ou recebem atributos extraidos da natureza. Ceci tem "lábios vermellos e úmidos (que) pareciam uma for da gardênia dos nossos campos "; seu hálito "doce e ligeiro exalava-se formando um sorriso"; sua tez cra "alva e pura como um floco de algodão "; enfim, ela é um misto de natureza e espírito infantil que brinca, faz travessuras espontâneas, inocentes, anjo e criança ao mesmo tempo.

Enquanto Cecilia tem cabelos louros, sua prima Isabel (na verdade irmã) é morena "tipo brasileiro em toda sua graça e formosura, com o encantador contraste de languidez e malicia, de indolência e vivacidade" (p. 34). D. Laureana, mãe de Ceci, nas horas de maior perigo era "animada pela sua fé. religiosa e pelo sangue nobre que girava nas suas veias" (p. 347). Mesmo seus pontos negativos são relativizados e suplantados pelas virtudes. Como diz o narrador, ela, "tirados os prejuizos, era uma boa senhora, e quando o seu 
coração se comovia, sabia compreender os sentimentos generosos" (p. 160).

Peri, integrado à família de D. Antônio, tinha "a beleza inculta da graça, da força e da inteligência" (p. 26). Como um cavaleiro medieval, rendia preito de vassalagem a Cecília, sua senhora, cujos desejos, por mais extravagantes que fossem, procurava cumprir com risco da própria vida. Sua natureza rude continha em gérmen a "nobreza de alma", que o elevava até à outra nobreza, a do sangue. D. Antônio de Mariz, ao saber de uma das muitas provas de dedicação de Peri, diz:

"E para mim uma das coisas mais admiráveis que tenho visto nesta terra, o caráter desse indio. Desde o primeiro dia que aqui estou, salvando minha filha, a siıa vida tem sido tum só ato de abnegação e heroismo. Crede-me, Alvaro, é um cavalheiro português no corpo de um selvagem" (p. 49).

Em outra ocasião, tomando os circunstantes por testemunhas, o fidalgo se dirige ao indigena, reconhecendo-o como do seu círculo:

"- Peri, disse ele, o que fizeste é digno de $i ;$; o que fazes agora é de um fidalgo. Teu nobre coração pode bater sem envergolharse sobre o coração de um cavalheiro português. Tomo-vos a todos por testemunha, que vistes um dia $D$. Antônio de Mariz apertar ao seu peito um inimigo de sua raça e de sua religião como a seu igual em nobreza e sentimentos" (p. 167).

Essas qualidades de Peri, extraídas do repertório dos valores e das virtudes pessoais da nobreza, sobrepõem-se ao que, sob outra perspectiva, poderia ser julgado defeito: o fato de ele abandonar seu próprio povoe tradições culturais. Aliás, o narrador transfere à personagem sua visão (e avaliação, naturalmente) das diferenças culturais, sem problematizá-las, contudo:

"Enquanto falava, um assomo de orgulho sel vagem da força eda coragem lhe brilhava nos olhos negros, e dava certa nobreza ao seu gesto. Embora ignorante, filho das florestas, era um rei; tinha a realeza da força. Apenas concluiu, a altivez do guerreiro desapareceu, ficou timido e modesto; já não era mais do que um bárbaro em face de criaturas civilizadas, cuja superioridade de edlucação o seu instinto reconhecia" (p. 115-6).

No ponto mais baixo da escala, encontramos vários tipos humanos. Por um lado, os serviçais ligados à casa de D. Antônio de Mariz, a quem dedicam obediência absoluta; e seu exército particular, "banda de aventureiros que lhe serviam nas stuas explorações e correrias pelo interior" (p. 17). Quanto aos indigenas, havia as "tribos selvagens, que, embora se retirassem sempre das vizinhanças dos ligares habitados pelos colonos e se evitranhassem pelas florestas, costumavam fazer correrias e atacar os brancos à traição" (p. 17). Compare-se essa referência com a cena da india morta "acidentalmente" por D. Diogo de Mariz. Se aí temos um termo eticamente marcado (à traição), lá o fato é descrito sem atribuição de qualquer sentido: "O moço ia atirar a um pássaro, e a india que passava nesse momento, recebera a carga da espingarda e caira morta". Tendo Peri testemunhado o fato, o narrador põe em sua boca uma reflexão sobre seu povo: 
"Oespetáculo que acabava de presenciaro entristecera; lembrouse de sua tribo, de seus irmãos que ele havia abandonado há muito tempo, e que talvez naquela hora eram também vitima dos conquistadores de sua terra, onde outrora viviam livres efelizes" (p. 87).

Mas isso não o impede de atribuir-lhe outra fala, agora sob o ângulo dos conquistadores:

"Ora, o indio conhecia a ferocidade desse povo sem pátria e sem religião, que se alimentava de carne humana e vivia como feras, no chão e pelas grutas e cavernas; estremecia só com a idéia de que pudesse vir assaltar a casa de D. Antônio de Mariz" (p.90).

Confirmando esse temor, já próximo ao desfecho da obra, os indigenas realmente ataeam a fortaleza do fidalgo, dando margem a Peri de defendê-la com todas as suas forças.

Finalmente, tendo função especial no enredo, encontramos a figura de Loredano, "aventureiro destemido e audaz", produto da metamorfose de Fr. Ângelo, um anjo decaído. Com seus asseclas, sempre desenhados com traços fortes: "instintos materiais", "inspiração infernal", "inteligência volada ao crime", "paixão brutal", "figuras sinistras", e os índios aimorés, de "ferocidade e espirito vingativo", encarnam as figuras do mal que ameaçam a familia de D. Antônio de Mariz e os valores que ela representa.

Alencar explicita todas as forças em jogo, dando-lhes forma e ação exteriores, como ocorre na épica homérica, cujo estilo Auerbach caracterizou por:

"representar fenômenos acabadamente, palpáveis e visiveis em todas as suas partes, claramente definidos em suas relaçôes espaciais e temporais"

Também n'Os Sertões encontramos muitos epitetos e expressões que caracterizam suas personagens. Muitas delas possuem a plasticidade das figuras mitolólicas antigas, barroquizadas por Euclides através da fusão de traços antitéticos: "Hércules -Quasimodo", representando a figura ao mesmo tempo forte e desajeitada do sertanejo; "centauro bronco", para designar a união do cavaleiro com seu animal; "campeador medieval desgarrado em seu tempo", para ilustrar a aparência do vaqueiro em sua roupa que se assemelha à armadura medieval, etc.

Quanto ao lugar geográfico, Os Sertões são situados em espaços ao mesmo tempo realistas e metafóricos. O autor fala em "variante trágica", para representar a passagem do burburinho de um vilarejo para o deserto da seca, ou em "tróia de laipa", para evocar a metamorfose da fortaleza troiana fragilizada pela miséria de Canudos.

A figura humana de Antônio Conselheiro é profusamente marcada pela dimensão lendária criada pela imaginação popular. Essa fonte de sentido dirige a transformação da pessoa histórica de Antônio Mendes Maciel à personagem Antônio Conselheiro. O processo vai promovendo a perda de todos os seus vinculos sociais: a mulher, a profissão, o nome, a moradia, ao que Euclides sintetiza: "Morrera por assim dizer". Mas, perdida a individualidade pessoal, 
a figura lendária do "anacoreta sombrio" vai ganhando dimensão míticoépica, espécie de instrumcnto da vontade coletiva, anônima e inconsciente. Nesse momento, diz o narrador-rcpórter: "cresceu tanto que se projetou na História".

Enfim, estavam prontos todos os ingredicntes épicos e romanescos para o desenvolvimento da ação bélica para cujo desfecho não bastou uma batalha. $\mathrm{Na}$ verdade, até a vitória sobre Canudos, pelo longo assédio que exigiu àquela "tróia de taipa", mimetiza à batalha imortalizada por Homero. Não certamente pela glória dos vencedores, mas pelo heró́smo dos vencidos.

\title{
Balanço final
}

Entre a "epopéia do coração" de Alencar e a "tróia de taipa" dos jagunços de Euclides vai a distância da euforia c entusiasmo implícitos na invenção de um dos mitos nacionais românticos à disforia no que csta implica de tensão e perplcxidade frentc a um real que impõe sua evidência. Vai a distância do romântico que inventa sua próprta origem, expressa sua ligação emotiva com a terra e sonha com seu futuro, e o homem da virada do século, que descobre um Brasil arcaico que pensava inexistente e com o qual não pode identificar-se.

Lembremos das palavras deixadas por Euclides em uma nota de campanha, palavras que são ao mcsmo tempo "mea culpa" e tomada de consciência de que a tarcfa de integração dos "nossos rudes patricios rransviados" seria uma tarcfa coletiva. Palavras, aliás, que ainda hoje não perderam atualidade:

"Sejamos justos - há alguma coisa de grande e solene nessa coragem estóica e incoercivel, no heroismo soberano e forte nos nossos rudes patricios transviados, e cada vez mais acredito que a mais bela vitória, a conquista real, consistirá no incorporá-los, amanhã, en breve definitivamente, à nossa existência política".

\begin{abstract}
This study tries to make an analysis of wo expressive works of lowailian literature: O Guarani (1857) and Os Sertoes (1902) ander the perspective of the epic myth. These works appeared in strategical periods of brazilian lilerature and life. The first by promoting a unification of the ideals of notionality rise (euphoric sense), typical from the Romantism: the second. by operating the acquistion of consciotssness on the imposses the brazilion society lived at that time (disphoric sense), a phase represented by the literature of Pre-ihodernism. Ev'en though they are diamerically oposed, both are integrated in the minteric-rhetoric iradition accomplished by the epic genre.
\end{abstract}

Key-words: The epic myth in hrasilian fiction; epic and literature; myth and hiterature: O Guarni and Os Serōes: rhetoric and hitcrature. 
ALENCAR, José de. O Guarani. l6a. edição. São Paulo, Mclhoramentos, 1968.

ANDRADE, Olimpio Sousa de. História e Interpretaçăo de Os Sertōes. Sño Paulo, EDART, 1960.

AUERBACH. Erich. Mimesis. A representação da ralidade na litcratura ocidental. Sĩo Paulo, Perspectiva, 1971.

CUNHA, Euclides da. Os Sertóes. 27a, ediçĩo. Brasilia, Editora da Universidade de Brasília, 1963. CURTIUS, Emst Robert. Literatura Etropeia e ldade Wédia Latina. Rio de Janeiro, Instituto Nacional do Livro, 1957.

GRASSI, Emesto. Arte e Mito. Lisbon, Livros do Brasil, s/d.

ROBERT, Marthe. Roman des origines et origines du romtrm. Paris, Grassel, 1972.

SILVA, Josć Maria Velho da. Liçóes de Rhetorica. Rio de Janeiro, Serafim José da Sitva, s/d. (1882). 